\title{
Nail haemorrhages in native highlanders of the Peruvian Andes
}

\author{
DONALD HEATH, PETER HARRIS, DAVID WILLIAMS, HEVER KRÜGER
}

From the Department of Pathology, University of Liverpool, Cardiothoracic Institute, University of London, and Cayetano Heredia Medical School, Lima, Peru

ABSTRACT Nail haemorrhages are of interest to the chest physician and cardiologist. While the common type in the distal part of the nail is produced by the minor trauma of daily life, the rarer form-scattered through the nail substance-appears to be related to hypoxaemia brought about by heart and lung disease. We thought it would be of interest to study a population which was naturally hypoxaemic because of living at high altitude. Accordingly we have studied the frequency and types of nail haemorrhage in Quechua Indians who are permanently exposed to the hypobaric hypoxia of the Andes. We found the haemorrhages to be common both in mestizos living on the $\vec{\bullet}$

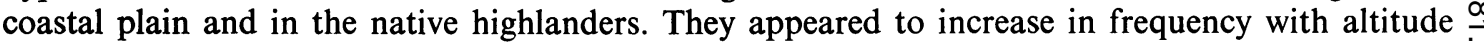
but were of the distal type and would thus seem to be the result of minor trauma as at sea level. However, just as in cases of cyanotic congenital heart disease at low altitude, those with exaggerated hypoxaemia and pronounced elevation of haematocrit-namely, subjects with Monge's disease (chronic mountain sickness)—-had scattered haemorrhages in the nail substance.

Haemorrhages in the nails are of interest to the chest physician and cardiologist for they may on occasion be related to serious disease of the heart or lungs. Thus they constitute a classical clinical sign which was originally associated with a diagnosis of subacute bacterial endocarditis over half a century ago. ${ }^{1}$ It has since come to be recognised that haemorrhages into the distal parts of the finger nails are very common and produced by the minor traumas of daily life. As such they have no clinical significance. However, hypoxaemic patients with a greatly elevated haematocrit not infrequently develop scattered haemorrhages in the nails, some extending as low as the root of the nail. They are found characteristically in patients with cyanotic congenital heart disease or such conditions as congenital arteriovenous fistula of lung. We thought it would be of interest to study a healthy population which was naturally hypoxaemic as a result of living at high altitude. Accordingly we have studied the frequency and types of nail haemorrhage in Quechua Indians who are permanently exposed to the hypobaric hypoxia of the Andes and

Address for reprint requests: Professor D Heath, Department of Pathology, University of Liverpool, PO Box 147, Liverpool L69 3BX. as a result develop systemic arterial unsaturation and compensatory polycythaemia. ${ }^{2}$

\section{Cases studied}

We studied the prevalence and distribution of $x$ haemorrhages in the finger nails of 63 mestizos at Lima $(150 \mathrm{~m})$, in 63 Quechua Indians at Cuzco $(3400 \mathrm{~m})$, and in 38 Quechuas at La Raya $(4200 \mathrm{~m})$. The last of these three areas was so desolate and remote as to preclude the study of a large number of subjects. We also studied four subjects with chronic $\frac{7}{2}$ mountain sickness (Monge's disease) at Cerro de Pasco $(4330 \mathrm{~m})$. Two of these were in the sixth $N$ decade, one in the fourth, and one in the fifth. In this $N$ condition on account of alveolar hypoventilation the $\mathrm{N}$ degree of systemic arterial unsaturation and the $\omega$ elevation of haematocrit already pronounced in 2 healthy Quechuas become exaggerated so that the haemoglobin level exceeds $23 \mathrm{~g} / \mathrm{dl}^{2}{ }^{2}$

\section{Results}

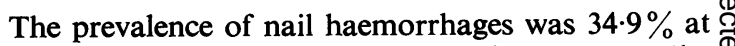
$150 \mathrm{~m}, 43.0 \%$ at $3400 \mathrm{~m}$, and $57.9 \%$ at $4200 \mathrm{~m}$. The $\stackrel{\mathbb{}}{\Omega}$ prevalence of the haemorrhages per decade in the 
Table Prevalance of nail haemorrhages per decade in the three groups of general population. The number of subjects studied in each decade is shown, the figure in brackets being those with haemorrhages

\begin{tabular}{|c|c|c|c|c|c|c|c|c|c|c|}
\hline \multirow{2}{*}{$\begin{array}{l}\text { Area of } \\
\text { study }\end{array}$} & \multirow{2}{*}{$\begin{array}{l}\text { Altitude } \\
\text { (m) }\end{array}$} & \multicolumn{9}{|c|}{ Decade } \\
\hline & & 2 & 3 & 4 & 5 & 6 & 7 & 8 & 9 & 10 \\
\hline$\overline{\text { Lima }}$ & 150 & $2(0)$ & $12(1)$ & $17(4)$ & $7(3)$ & $14(5)$ & $6(5)$ & $4(3)$ & $1(1)$ & 0 \\
\hline Cuzco & 3400 & $2(0)$ & $8(3)$ & $11(3)$ & $13(6)$ & $14(10)$ & $11(5)$ & $1(0)$ & $2(2)$ & $1(0)$ \\
\hline La Raya & 4200 & $3(1)$ & $4(3)$ & $16(10)$ & $8(5)$ & $5(3)$ & $2(0)$ & 0 & 0 & 0 \\
\hline \multirow{2}{*}{\multicolumn{2}{|c|}{$\begin{array}{l}\text { Percentage with nail } \\
\text { haemorrhages }\end{array}$}} & & & & & & & & & \\
\hline & & 14 & 29 & 39 & 50 & 54 & 53 & 60 & & \\
\hline
\end{tabular}

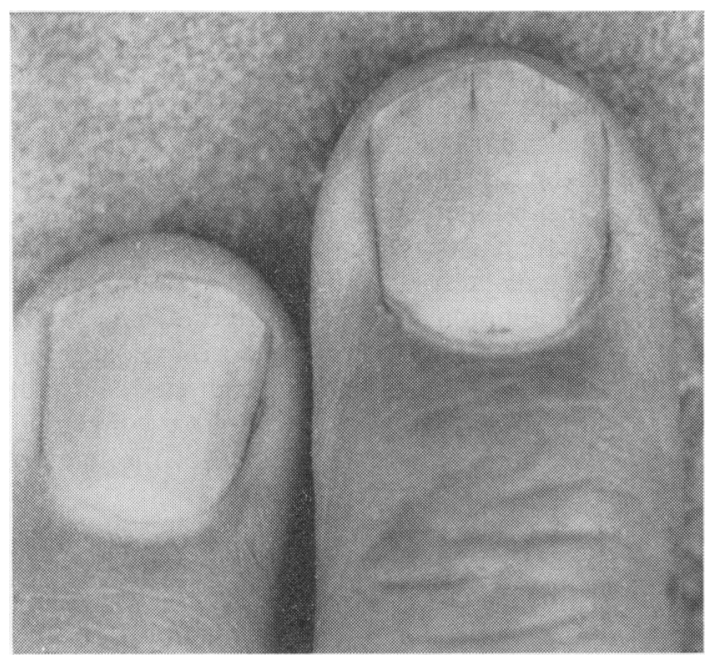

Fig 1 Linear haemorrhages in the distal part of the third left fingernail in a male mestizo of 54 years who was born and lived all his life at Lima $(150 \mathrm{~m})$. The haemorrhages are on the line of separation of nail plate from nail bed and are typical of those found at sea level.

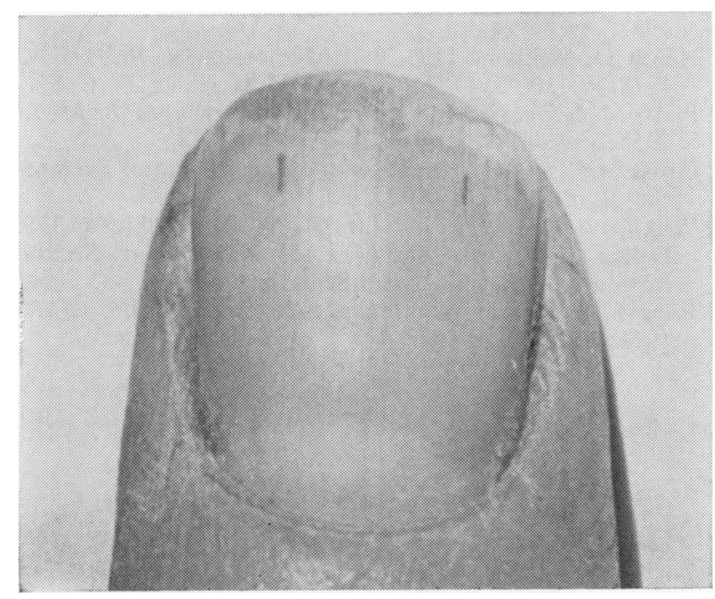

Fig 2 Two linear haemorrhages in the distal part of the third right fingernail in a male Quechua Indian of 32 years who is a native highlander of La Raya (4200 m).

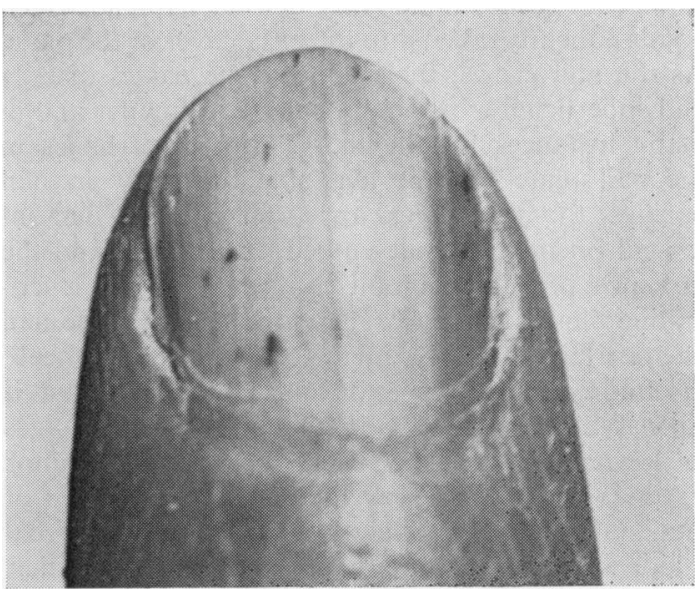

Fig 3 Haemorrhages scattered throughout the nail substance in the fingernail in a male Quechua Indian of 35 years who is a native highlander of Cerro de Pasco $(4330 \mathrm{~m})$ and who has developed chronic mountain sickness with pronounced arterial oxygen unsaturation and a greatly elevated haematocrit.

three groups of the general population is shown in the table. There was an overall progressive'increase until middle life. All four patients with chronic mountain sickness had haemorrhages in their nails.

The nail haemorrhages in the lowlanders from Lima (fig 1) and in the healthy highlanders from Cuzco and La Raya (fig 2) were reddish-brown in colour, punctate or linear, and situated in the nail plate at the line of its separation from the underlying nail bed. They were identical in appearance to haemorrhages that we have observed frequently in subjects at sea level in Britain. ${ }^{3}$ In contrast those in the subjects with chronic mountain sickness were scattered throughout the nail plate extending deep down into the nail as low as the root of the nail (fig 3).

\section{Discussion}

Our studies show that nail haemorrhages are common in the mestizos of the coastal plain of Peru just as they are in Sheffield ${ }^{4}$ and London. ${ }^{5}$ Their prevalence appears to increase with altitude. The 
variety which is to be found in both the coastal mestizo and in the native highlanders of Cuzco $(3400 \mathrm{~m})$ and La Raya $(4200 \mathrm{~m})$ corresponds to that which occurs so commonly at sea level in Britain and which we have studied previously. ${ }^{3}$ These haemorrhages are of no clinical significance and occur at the line of separation of the nail plate from the underlying nail bed (figs 1 and 2). They are linear and appear to arise as a result of bleeding from small capillaries in the underlying dermal papillae which is subsequently taken into the basal layer of the plate. As the nail grows, the haemorrhage passes distally and superficially, becoming paler and smaller and in many instances fragmented. The haemorrhages in the nail plate become available for study in nail parings; the histological appearances can be demonstrated on methacrylate-embedded material and the presence of altered blood confirmed by the leucoaniline blue technique. ${ }^{3}$ The pathology of these nail haemorrhages is very similar to that of "black-heel" in children, ${ }^{6}$ and the importance of this is that it strongly supports the view that nail haemorrhages in lowlanders are the result of repeated minor trauma. In the same way the nail haemorrhages of highlanders are also likely to be caused by repeated minor trauma encountered in the course of their daily life in the mountains. The added factor responsible for the increased incidence is likely to be hypoxia because of the diminished barometric pressure of the mountain environment. The increase in prevalence of nail haemorrhages with increasing age is unlikely to be the result of increasing manual activity. Presumably it is an expression of increasing fragility of the capillaries or lack of support to them by the surrounding tissues.

The exaggeration of the degree of hypoxaemia and compensatory polycythaemia in the Indians with chronic mountain sickness brings about not only an increase in the incidence of nail haemorrhages but a change in their distribution in the nail plate. Thus in this disease they are more numerous and scattered throughout the substance of the nail to its root (fig 3). This is also the distribution found in cases of cyanotic congenital heart disease where the haemorrhages are also likely to be caused by the effects of hypoxia and raised haematocrit on the capillaries deep to the nail substance.

Nail haemorrhages also develop in climbers at high altitude. Thus Rennie ${ }^{7}$ found that on an expedition to Dhaulagiri, Nepal $(8170 \mathrm{~m})$, the sixth highest mountain in the world, he developed numerous haemorrhages in the distal parts of his fingernails. After a restful evening spent at $5880 \mathrm{~m}$ he developed 50 thin red longitudinal streaks in his finger and thumbnails. In the previous five weeks he had been engaged in manual work transporting loads from $760 \mathrm{~m}$ to $5880 \mathrm{~m}$. Seven fellow climbers also developed nail haemorrhages. Climbing at high altitude seems to provide an appropriate combination of a rising haemoglobin level and repeated trauma to the hands to produce such haemorrhages.

In conclusion, there appear to be two recognisable forms of nail haemorrhage at both low and high altitude. The distal form is caused by minor trauma and is very common in healthy subjects. The rarer, scattered type is related to pronounced hypoxaemia, the basis for this being Monge's disease at high altitude and such conditions as cyanotic congenital heart disease or arteriovenous fistula of the lung at sea level.

We acknowledge gratefully receipt of research grants from the British Heart Foundation and the Wellcome Trust which made possible the expedition to the Andes during which this study took place.

\section{References}

${ }^{1}$ Horder T. Discussion on the clinical significance and course of subacute bacterial endocarditis. $\mathrm{Br}$ Med $\mathrm{J}$ $1920 ; 2: 301-4$.

${ }^{2}$ Heath D, Williams DR. Man at high altitude. Second edition. Edinburgh and London: Churchill Livingstone, 1981.

${ }^{3}$ Heath D, Williams DR. Nail haemorrhages. Br Heart $J$ $1978 ; 40: 1300-5$.

4 Platts MM, Greaves MS. Splinter haemorrhages. Br Med J $1958 ; 2: 143-4$.

${ }^{5}$ Gross NJ, Tall R. Clinical significance of splinter haemorrhages. Br Med J $1963 ; 2: 1496-8$.

6 Wilkinson DS. Black heel. In: Rook A, Wilkinson DS, Ebling FJG, eds. Textbook of dermatology. Second edition. Oxford: Blackwell Scientific, 1972:427-8.

7 Rennie D. Splinter haemorrhages at high altitude. JAMA 1974;228:974. 